\title{
THE SEMI-QUANTITATIVE STUDY OF MAGNETIZATION PROCESS ON MILLING AND REANNEALING OF BARIUM HEXAFERRITE $\left(\mathrm{BaO} .6 \mathrm{Fe}_{2} \mathrm{O}_{3}\right)$
}

\author{
Ridwan $^{1^{*}}$, Mujamilah ${ }^{1}$ and A. Johan ${ }^{2}$ \\ 'Centre for Technology of Nuclear Industry Materials, BATAN \\ Kawasan PUSPIPTEK, Serpong- Indonesia \\ ${ }^{2}$ Departement of Physics, Faculty of Mathematics and Natural Science, \\ Sriwijaya University, Palembang 30662 \\ Received 16 February 2009; Received in revised form 1 September 2009; Accepted 23 November 2009
}

\begin{abstract}
THE SEMI-QUANTITATIVE STUDY OF MAGNETIZATION PROCESS ON MILLING AND REANNEALING OF BARIUM HEXAFERRITE $\left(\mathrm{BaO}_{6} 6 \mathrm{Fe}_{2} \mathrm{O}_{3}\right)$. Barium hexaferrite $\left(\mathrm{BaO} .6 \mathrm{Fe}_{2} \mathrm{O}_{3}\right)$ is as a hard magnetic material with good chemical stability which has been intensively used as permanent magnet components. Many works have been done in order to improve their magnetic properties either through chemical process or powders metallurgy technique. In this work, commercial $\mathrm{BaO} .6 \mathrm{Fe}_{2} \mathrm{O}_{3}$ was milled using high-energy milling machine for 10,20 and 30 hours and followed by reannealing for 3 hours at $1000{ }^{\circ} \mathrm{C}$ in air. X-ray diffraction pattern indicate no phase decomposition occurred caused the mill processing, annealing of milled powders recovered the crystal system and promoted crystallite growth. The magnetic hysteresis curve measured by vibrating sample magnetometer (VSM) shows the coercivity of annealed $\mathrm{BaO} .6 \mathrm{Fe}_{2} \mathrm{O}_{3}$ increases to two times higher than the original one. By using Jiles-Atherton model, all the hysteresis parameters $M_{s}, k, \alpha, a$ and $c$, have been determined adopted to the Genetic Algorithm (GA). The analyzed hysteretic parameters obtained from this work is congruent to the change of magnetic properties of as-milled and annealed powders of barium hexaferrite.
\end{abstract}

Keywords : Barium hexaferrite, high-energy milling, magnetic properties, J-A model, XRD,VSM

(c) 2009 Atom Indonesia. All rights reserved.

\section{INTRODUCTION}

Barium hexaferrite, $\mathrm{BaO} .6 \mathrm{Fe}_{2} \mathrm{O}_{3}$ is hard magnetic material having fairly high coercivity, high Curie temperature, large saturation magnetization and good chemical stability. Therefore, this material has been intensively used as permanent magnets, components of high frequency devices or magnetic recording media. Many aspects of these materials have been explored including their crystal structure, as well as magnetic properties. The various routes of preparing barium hexaferrite powders have been carried out by means of powder metallurgy [1], chemical precipitation

\footnotetext{
Corresponding author.

E-mail address: ridwan@batan.go.id (Ridwan)
} 
method [2], sol-gel process and organo-metalic precursor [3]. However, recently the high-energy ball milling (HEM) technique has been extensively used to produce hard magnetic ferrite powders. This ball milling technique is quite simple to produce very fine powders (in the nanometer scale) of hard magnetic ferrite. The optimum magnetic properties of barium hexaferrite can be achieved by subsequently annealing the ball milled powders at elevated temperatures range of $800-1300^{\circ} \mathrm{C}$. Ultrafine particles are desired as starting precursor in order to produce hard magnetic materials, with high-saturation magnetization and coercivity. Where the coercivity is determined by the factors of 1) the particle size 2) the magnetic anisotropy, and 3) the shape of particles [4].

High-energy ball milling is simple processing method to produce nanometer particle size of barium hexaferrite and prospective to develop for mass scale production. Almost all metallic and ceramic compounds could be powderized by this technique [5]. In spite of extensive research of milling effect on the hard magnetic properties of hexaferrite (e.g. $\mathrm{SrO} 6 \mathrm{Fe}_{2} \mathrm{O}_{3}$ ), quantitative study about magnetization process dependent on milling time and annealing temperature have not been reported. In this work, the milling effect of barium hexaferrite powders to their structural and magnetic properties followed by annealing at $1000{ }^{\circ} \mathrm{C}$ for 3 hours in the air we investigated. The measured magnetic hysteresis curve of as milled and annealed powders were compared to the calculated hysteresis adopted from Jiles-Atherton (JA) method [6]. In this paper, all of five parameters of hysteresis $M_{s}, k, \alpha, a$ and $c$, resulted from calculated hysteresis of as milled and annealed barium hexaferrite have been determined.

\section{Jiles Atherton Hysteresis Model}

The Jiles-Atherton (JA) model is a physically based model that includes the different mechanisms that take place at magnetization of a ferromagnetic material. In the JA model the total magnetization $M$ is calculated from the magnetic field $H$. $M$ is represented by the sum of the reversible magnetization $M_{\text {rev }}$ due to the domain wall bending and the irreversible magnetization $M_{\text {irr }}$ component due to the wall displacement [7].

$$
M=M_{r e v}+M_{i r r}
$$

The $M_{\text {rev }}$ is related to the anhysteretic or ideal magnetization express by the following equation :

$$
M_{r e v}=c\left(M_{a n}-M_{i r r}\right)
$$

Where $c$ is a reversibility coefficient, and $M_{a n}$ is the phenomenological representation of anhysteretic magnetization proposed by Langevin as : 


$$
M_{a n}=M_{s}\left\{\operatorname{coth}\left(H_{e} / a\right)-\left(a / H_{e}\right)\right\}
$$

Where $a=k_{B} T / \mu_{0} m ; k_{B}$ Boltzman constant, $T(K), m$ is magnetic moment in unit volume, and $\mu_{0}$ is permeability in vacuum. Here, $M_{s}$ is saturation magnetization, and

$$
H_{e}=H+\alpha M
$$

is the effective field taking into account the domain interactions, and $\alpha$ is a model parameter. After some mathematical arrangement the differential equation can be obtained

$$
M_{i r r}-M_{a n}+k \delta \mathrm{d} M_{i r r} / \mathrm{d} H_{e}=0
$$

where the parameter $k$ is linked to the coercive field, the parameter $\delta$ is equal to sign of $H_{e}$. By substituting (4) into (5) and rearranging the terms, it can be obtained the well known differential equation of Jiles-Atherton model written in the form

$$
\mathrm{d} M / \mathrm{d} H=(1-c)\left[\left(M_{a n}-M_{i r r}\right) /\left\{\delta k-\alpha\left(M_{a n}-M_{i r r}\right)\right\}+c\left(\mathrm{~d} M_{a n} / \mathrm{d} H\right)\right]
$$

To extract optimal parameters of $\alpha, a, c, k$ and $\mathrm{M}_{\mathrm{s}}$, for the Jiles-Atherton model of hysteresis as shown by equation (6), we used the genetic algorithm approach developed in MATLAB [8,9].

\section{EXPERIMENTAL METHODS}

Commercial barium hexaferrite $\left(\mathrm{BaO} .6 \mathrm{Fe}_{2} \mathrm{O}_{3}\right)$ powders were ball milled for 10, 20, 30 hours in air with stop after every 90 minutes milling run for cooling the motor. The milling were performed using high-energy ball milling SPEX CertiPrep 8000M Mixer/ Mill, using stainless steel vials and balls, in a ball- to-powder weight ratio of $5: 1$. The milled powders were divided in two parts, ones for directly structural and magnetic characterizing and others were annealed at temperature of $1000{ }^{\circ} \mathrm{C}$ for 3 hours in air. As milled and annealed powders were structurally characterized by x-ray diffraction (XRD) using $\mathrm{Cu}-\mathrm{K} \alpha$ incident radiation and the crystallite sizes were evaluated averaging over the values of peaks broadening obtained from refinement of measured $\mathrm{x}$-ray data by Rietveld method using Rietan-2000[10]. The magnetic hysteresis loops for as milled and annealed powders were measured in a vibrating sample magnetometer (VSM), up to $800 \mathrm{kA} / \mathrm{m}$ at room temperature. The all five parameters of hysteresis were determined by fitting measured hysteresis loop using JA model implemented in MATLAB. 


\section{RESULT AND DISCUSSION}

Figure 1 shows the XRD pattern of original barium hexaferrite and after milling at 10,20 and 30 hours in air.

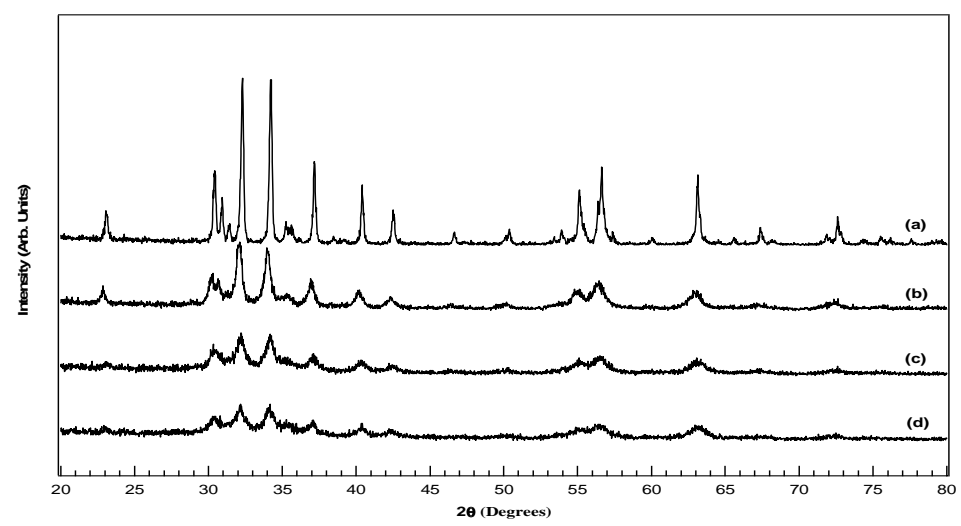

Figure 1. XRD patterns for barium hexaferrite powders milled at various time of (a) $0 \mathrm{hr}$ (b) $10 \mathrm{hrs} \mathrm{(c)} 20 \mathrm{hrs}$ and (d) $30 \mathrm{hrs}$.

The diffraction patterns of as-milled powders show no phase transition occurred during the milling time. However, the intensities of diffraction peaks were decreases and become broaden with the prolonged of milling time which may be due to the reduced of crystallite size, crystal defects or accumulation of mechanical stress during the powders milling. The average crystallite sizes were determined using Scherer formula, where the peak positions and full wave half maximum $(F W H M)$ were obtained from refinement of the measured x-ray diffraction data by Rietveld method using Rietan'2000, are 13, 9, and 8 nanometers after milling 10, 20 and 30 hours respectively. The x-ray diffraction pattern of milled powders which were annealed for 3 hours at $1000{ }^{\circ} \mathrm{C}$ in air can be seen in Figure 2. These observed x-ray data show that the intensities were increasing and the peaks become narrower, due to the increase of the crystallite sizes. The obtained crystallite size determined with the same procedure as milled powders are 29, 33 and 43 nanometers corresponding to powders milled at 10,20 and 30 hours respectively. This increasing of crystallite size during the annealing process is only related to the re-crystallization mechanism, because no other phase than barium hexaferrite is involved in the annealed powders. The enhancement of crystal growth during annealing for the smaller particles, because the shape of smaller particles are relative homogeneous and their compacted powders were more dense compared to the coarse particles, therefore mechanism of atomic interdifusion are easier during annealing which promoted enhancement crystal growth. 


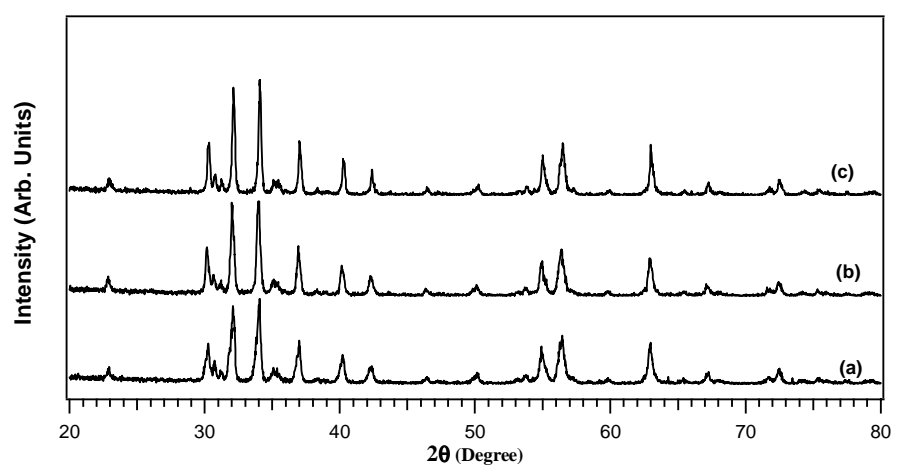

Figure 2.XRD patterns for barium hexaferrite powders annealed for $3 \mathrm{hrs}$ at $1000{ }^{\circ} \mathrm{C}$ after milling at various of time a) $10 \mathrm{hrs} \mathrm{b)} 20 \mathrm{hrs} \mathrm{c)} 30 \mathrm{hrs}$.

Figure 3 shows hysteresis loops of barium hexaferrite before and after milling for 10, 20 and 30 hours.
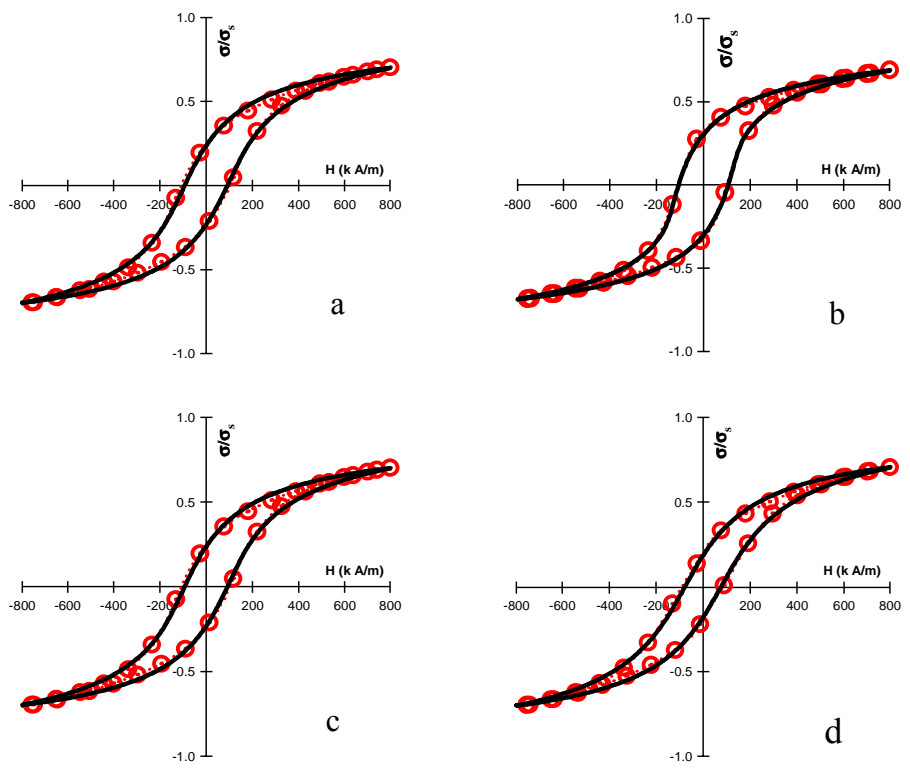

Figure 3. Hysteresis loops barium hexaferrite powders before milling (a) and after milling for (b) $10 \mathrm{hrs} \mathrm{(c)} 20 \mathrm{hrs} \mathrm{(d)} 30 \mathrm{hrs;}$;here (O) is observed data and solid lines are calculation results by using JA model.

In Figure 3, magnetic saturation defined as $\sigma_{\mathrm{s}}(\mathrm{emu} / \mathrm{g})$ and observed magnetization $(\sigma)$ was normalized to the magnetic saturation obtained from 
calculation by using JA model. All observed hysteresis loops of barium hexaferrite before and after milling were measured using VSM with maximum external field of $800 \mathrm{k} \mathrm{A} / \mathrm{m}$, approximately match with hysteresis loop calculated by using JA model. The hysteresis parameters obtained from fitting the observed hysteresis loops of as-milled barium hexaferrite adopted the JA model is shown in the Table 1.

Table 1. Hysteresis loops parameters, obtained from fitting the observed data of as milled barium hexaferrite powders by JA model.

\begin{tabular}{|c|c|c|c|c|c|}
\hline Sample & $\sigma_{s}(\mathrm{emu} / \mathrm{g})$ & $k$ & $\alpha$ & $A$ & $c$ \\
\hline Original & 105.0123 & $1.7820 \mathrm{e}+05$ & $1.1120 \mathrm{e}+04$ & $3.9561 \mathrm{e}+05$ & 3.9049 \\
\hline Milled 10 hrs & 77.7557 & $1.1952 \mathrm{e}+05$ & $1.7601 \mathrm{e}+04$ & $4.9501 \mathrm{e}+05$ & 5.5494 \\
\hline Milled 20 hrs & 55.5563 & $1.1721 \mathrm{e}+05$ & $1.5427 \mathrm{e}+04$ & $3.6804 \mathrm{e}+05$ & 4.2703 \\
\hline Milled 30 hrs & 40.4899 & $1.0960 \mathrm{e}+05$ & $1.6597 \mathrm{e}+04$ & $3.2539 \mathrm{e}+05$ & 4.6037 \\
\hline
\end{tabular}

Figure 4, shows the hysteresis loops of milled barium hexaferrite after annealing for $3 \mathrm{hrs}$ at $1000{ }^{\circ} \mathrm{C}$ in air. Annealed treatment to the milled powders, promoted re-crystallization of barium hexaferrite, recovered the crystal defects and released the residual stress during the milling process, therefore their magnetic properties also recovered.
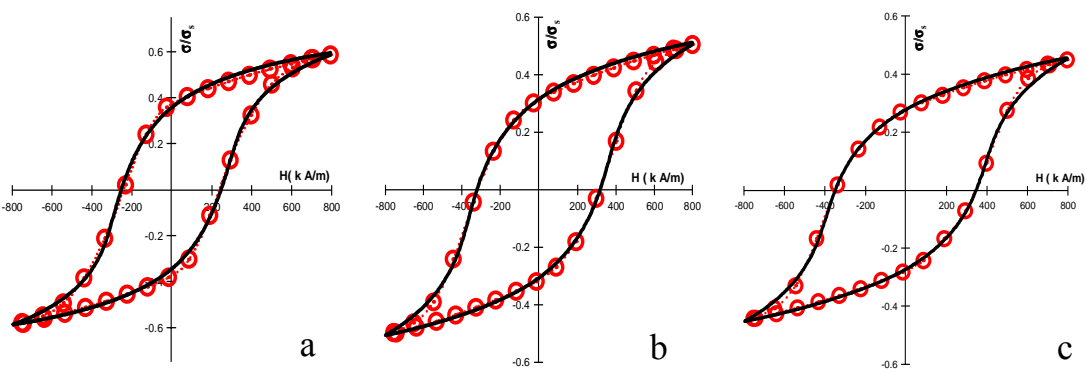

Figure 4. Observed ( $\mathrm{O}$ ) and calculated ( - )hysteresis loops of annealed Barium Hexaferrite powders for $3 \mathrm{hrs}$ at $1000{ }^{\circ} \mathrm{C}$, which have been milled for (a) $10 \mathrm{hrs} \mathrm{(b)} 20 \mathrm{hrs}$ and (c) $30 \mathrm{hrs}$.

As it was mentioned before, the high coercivity of hard magnetic materials is desirable for their application in many devices. Considering the sample milled for $30 \mathrm{hrs}$ and followed by annealing for $3 \mathrm{hrs}$ at $1000{ }^{\circ} \mathrm{C}$, observed intrinsic coercivity $\left(H_{c i}\right)$ increased by a factor of two compared to the original one (synthesis by conventional ceramic method) that was $349 \mathrm{k} \mathrm{A} / \mathrm{m}$. Quantitative analysis results using JA model to the hysteresis loops of barium hexaferrite powders after milling 10,20 and $30 \mathrm{hrs}$ and followed by annealing for $3 \mathrm{hrs}$ at $1000{ }^{\circ} \mathrm{C}$, is shown in Table 2. The hysteresis loop parameter $k$, is defining the pinning site density of domain wall, which to be 
the major contribution to the hysteresis[7]. Therefore, the change of this parameter closely related to the coercivity. Quantitative analysis of parameter $k$, obtained from the as-milled and annealed powders related to the changed of coercivity, can be seen in Figure 5.

Table 2. Hysteresis loops parameters, obtained from fitting by JA model to the observed data of barium hexaferrite powders annealed for $3 \mathrm{hrs}$ at $1000{ }^{\circ} \mathrm{C}$ after subsequently milling

\begin{tabular}{|c|c|c|c|c|c|}
\hline Sample & $\sigma_{s}(\mathrm{emu} / \mathrm{g})$ & $k$ & $A$ & $a$ & $c$ \\
\hline Milled 10 hrs & 117.6756 & $3.2566 \mathrm{e}+05$ & $1.7013 \mathrm{e}+04$ & $6.6530 \mathrm{e}+05$ & 2.4085 \\
\hline Milled 20 hrs & 136.6143 & $3.6989 \mathrm{e}+05$ & $1.9860 \mathrm{e}+04$ & $9.4757 \mathrm{e}+05$ & 1.8531 \\
\hline Milled 30 hrs & 146.9870 & $3.8677 \mathrm{e}+05$ & $2.5520 \mathrm{e}+04$ & $1.3184 \mathrm{e}+06$ & 1.9771 \\
\hline
\end{tabular}
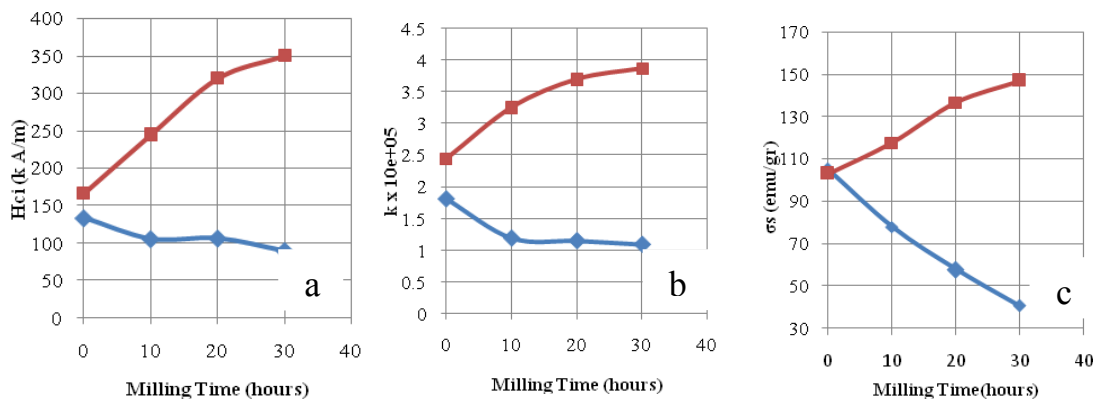

Figure 5. (a) The coercivity values observed for the as-milled barium hexaferrite powders $(\diamond)$ and after reannealing $(\square)$; (b) Hysteresis parameter $k$, obtained from hysteresis analyzed of as-milled powders $(\diamond)$ and after re-annealing process $(\square)$; (c) the changed of magnetic saturation as milled $(\diamond)$ and after milling followed by annealing process $(\square)$.

Figure 5 (a) and (b), shows that the change of barium hexaferrite coercivity under milling and after annealing follow the change of hysteresis loops parameter, $k$. Increasing of $k$ parameter, as it was predicted related to the annealing process which reduced the crystal defects and stress due to the milling, in agreement with the results shown by XRD data. The crystal perfection is also representing by the change of magnetic saturation before and after milling followed by annealing, as shown in Figure 5c. The magnetic saturation $\left(\sigma_{\mathrm{s}}\right)$ of milled powders followed by subsequent annealing were higher than the original one as was obtained from calculation of their hysteresis loops by using JA model. Other calculated hysteresis parameters $\alpha, a$ and $c$ can be seen in Figure $6 \mathrm{a}, \mathrm{b}$ and c. $\alpha$ is a mean field parameter defining the magnetic coupling between domain in the material as shown by equation (4). The increases of this parameter with annealing process may 
related to the reduction of defects upon re-crystallization, which promoted the better magnetic interaction mechanism in the material. While $a$, is Langevin parameter corresponding to the anhysteretic curve (3), which is also related to the magnetic saturation. The $c$ parameter is defining by the amount of reversible magnetization due to the wall bowing and reversal rotation, included in the magnetization process. The decrease of $c$ with annealing could be related to the increase of coercivity as shown in Figure $5 \mathrm{a}$.
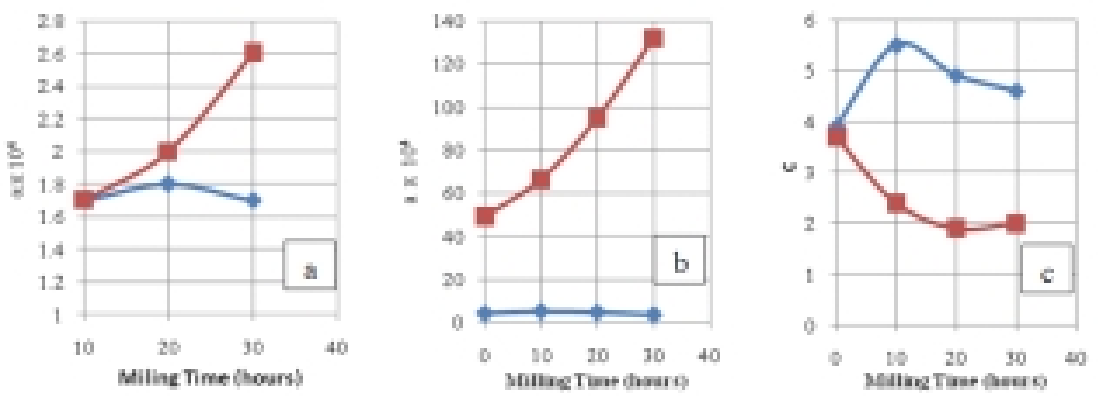

Figure 6. (a) The $\alpha$ parameter, (b) $\alpha$-parameter and (c) $c$-parameter obtained from calculated hysteresis curve of barium hexaferrite milled for 10,20 and $30 \mathrm{hrs}(\diamond)$ and annealed mill powders for $3 \mathrm{hrs}$ at $1000{ }^{\circ} \mathrm{C}(\square)$

The overall results shows that enhancement of magnetic properties of barium hexaferrite produced by conventional ceramic method could be achieved if the starting powders reduced down to nanometer scale. Reduction of crystal defects and residual stress during the annealing process may promote the enhancement of magnetic properties.

\section{CONCLUSION}

Re-crystallization of barium hexaferrite after high energy ball mill followed by annealing process not only reconstructed the crystal structure, but also increased their magnetic properties representing by the higher observed coercivity and magnetic saturation compared to the original powders. Increasing of coercivity value two times higher than unprocessed powders seem to be not only depending on smaller crystal size but also supported by less crystal defects in the materials. The theoretical approach to the observed hysteresis loops for as-milled and milled powders followed by annealing process by using Jiles-Atherton model could determined the five hysteresis parameters representing the magnetization process in hard magnet barium hexaferrite. 


\section{REFERENCES}

1. CABANAS, M.V., CALBET, J.M.G., CARVAJAL and J.R., REGI., J. Sol. Stat. Chem., 111, 229-237 (1994).

2. JANASI, S.R., EMURA, M., LANDGRAF, F.J.G., RODRIGUES, D., J. Magn. Magn. Mater., 238, 168-172 (2002).

3. SANG WON LEE, SUNG YONG AN, SAM JIN KIM, IN-BO SHIM, and CHUL SUNG KIM, IEEE Trans. Magn., 39, 5, 2899-2901 (2003).

4. LIU, X., BAI, J., WEI, F., and YANG, Z., J. Appl. Phys., 87, 6875 (2000).

5. MATTEAZZI, P., BASSET, D., MIANI, F. and LECAER, G., :’Nano Structured Materials", Pergamon Press Ltd., 2, 217 (1997).

6. JILES, D.C. and ATHERTON, D.L., J. Phys. D. Appl. Phys., 17, 1265-1281 (1984).

7. JILES, D.C. and ATHERTON, D.L., J. Magn. Magn. Mater, 61, 48-60 (1986).

8. YANI, A., RIDWAN and MUJAMILAH, Indonesian Journal of Materials Science, Special Edition, 85-90 (2006).

9. WILSON, P.R., ROSS, J. N., and BROWN, A.D., IEEE Trans. Magn., 37, 2, 989-993 (2001).

10. IZUMI, F. and IKEDA,T., Mater. Sci. Forum, 198, 321-324 (2000). 